Pikas E., Koskela L., and Liias R. (2017). "Design Management in a Design Office: Development of the Knowledge Base” In: LC3 2017 Volume II - Proceedings of the 25th Annual Conference of the International Group for Lean Construction (IGLC), Walsh, K., Sacks, R., Brilakis, I. (eds.), Heraklion, Greece, pp. 539-546. DOI: https://doi.org/10.24928/2017/0316

\title{
DESIGN MANAGEMENT IN A DESIGN OFFICE: DEVELOPMENT OF THE KNOWLEDGE BASE
}

\author{
Ergo Pikas ${ }^{1}$, Lauri Koskela ${ }^{2}$, Roode Liias ${ }^{3}$
}

\begin{abstract}
In this second paper in a series of three, the aim is to develop a theoretical knowledge base for design science research (DSR) activity within the next paper. This is primarily a literature review based paper, inspired by the problems summarized in the first paper. The paper starts with a description and justification of the prototheory of design and design rhetoric. It has been argued that the design science has been concerned with the artefact rather as a technical than a social phenomenon. It is opportune to propose that the proto-theory of design and design rhetoric represent different, yet related dimensions of a productive act (techne). These concepts provide the necessary prescription for the root cause analysis of the problems addressed within the first paper and practical design and design management conceptualization within the third paper.
\end{abstract}

Keywords: Design, proto-theory of design, rhetoric, design rhetoric

\section{INTRODUCTION}

Within the first paper, we concluded that it is the poor conceptualization of design and design management that has led to the bad consequences. Furthermore, we argue that design management cannot decouple from and ignore the fundamentally complex nature of design task; a term used to describe the invention, planning, and realization of both tangible and intangible products (Buchanan, 2001). This complexity is illustrated by the pluralism of design conceptualizations (Buchanan, 2009), including different perspectives, subject matter, strategies of inquiry and methodologies. To shed some light on the design within the context of production science, Koskela and Ballard (2013) have proposed that the two ancient methods, including the method of analysis (proto-theory of design) and rhetoric are separate, yet complementary methods for design conceptualization. Both fall into techne (Aristotle, 2001); i.e. that these are productive and creative acts of producing either geometric figure or persuasive speech.

In this second paper in a series of three, we pursue the development of a theoretical knowledge base. This would eventually be the basis for the design science research (DSR) activity, to be presented in the third paper. First, the method is described, next relevant theories are described, and interpretations and comparisons to existing design conceptualization complete the paper.

1 Aalto University, Department of Civil Engineering, ergo.pikas@aalto.fi and Tallinn University of Technology, Faculty of Civil Engineering, ergo.pikas@ttu.ee

2 University of Huddersfield, School of Art, Design and Architecture

3 Tallinn University of Technology, Faculty of Civil Engineering 


\section{METHOD}

As in the first paper, also here we have adapted the DSR methodology (Kuechler and Vaishnavi, 2011), which Hevner (2007) describes as process of achieving knowledge and understanding of a problem domain by building and application of a designed artefact. Within this study, the focus is on the development of knowledge base, primarily through literature study method (Figure 1). We approach the development of knowledge base through the perspective of production science (Koskela and Ballard, 2012, Koskela, 2000), or in other words techne (Meos, 2011). After articulating the basic ideas of the proto-theory of design and design rhetoric, we provide an interpretation and comparison of these concepts within the context of the wider design literature.

1) Environment

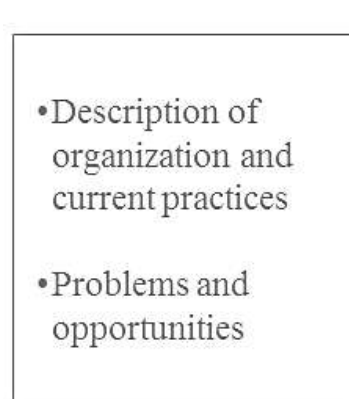

3) Design Science Research

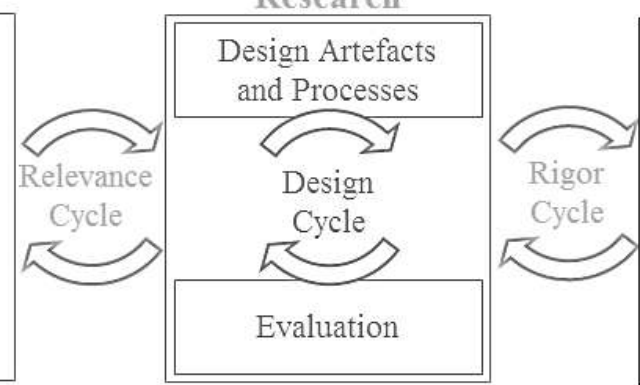

\section{2) Knowledge Base}

- Two Pillars of Design Production Theory: Proto-Theory of Design and Rhetoric

-State of the art building design and management practices

Figure 1. Design science research methodology for developing future design process and management model (adapted from Hevner (2007)).

\section{Two Pillars of Design Production}

We start with the discussion by Kroes (2002) to justify the selection of proto-theory of design and design rhetoric as relevant prescriptions for design conceptualization. Kroes (2002) argues that Simon's view on artefact's 'inner' and 'outer' environment is limited and must be expanded. Kroes reasoned that the focus must shift from considering artefacts merely as technical to considering these also as social within the context of intentional human action. Thus, he proposed the concept of "dual nature of artefacts".

In this work, it is opportune to propose that the proto-theory of design and design rhetoric represent different but related dimensions of a productive act (techne). These concepts provide the explanation for addressing artefacts as technical and social phenomena.

\subsection{Proto-theory of Design as Rational Reasoning}

Koskela and Kagioglou argue that despite that ancient method of analysis (geometry) and its understanding was lost, including also the precise contents of analysis and synthesis, the conception of (engineering) design as rational reasoning has persisted throughout the history, to be the common assumption in contemporary (engineering) design theories (Koskela and Kagioglou, 2006). Based on the work of Aristotle and the Greek geometer Pappus, Koskela et al. (2014) identified seven key properties of the method of analysis: its start and end points, types of analysis, its stages, the types of reasoning involved, unity of two directions, the strategy of reasoning and the targeted outcomes.

In ancient method of analysis, the start and the ends points have been described to be qualitatively different. It is the movement from something given (start of analysis) to 
something known (the end of analysis/start of synthesis). This stream is called analysis, including two stages, discovery and design embodiment, and three different (regressive, decomposition and transformation) types of reasoning (Koskela et al., 2014). Within contemporary design literature, two stages describe the two different time periods within the design process and/or two stages of the design reasoning.

Analysis progresses from requirements (functional and non-functional) to function allocation (concept) and from concept to design solution (structure/form) in two-step abductive reasoning (Kroll and Koskela, 2016). The progression from one to the next state is informed by continuously comparing the designs (either concept or solution) to the design goal (requirements). These concepts introduce the notions of iteration and heuristics into the analysis (Koskela et al., 2014, Ullman, 2009).

Design process is also recursive, meaning that every decision made during two-step abductive reasoning or in previous process stage, frames or constrains the subsequent decisions, including downstream design decisions (Ullman, 2009) and synthesis (making). Simply, for example decisions made in conceptual design, bound and constrain the solution space within the following design stages.

The end of analysis/start of synthesis (something known) is the beginning for another stream called synthesis (making). In synthesis, as a first step, the design solution(s) chosen are communicated/transmitted and implemented in tangible medium. From there design progresses by two different modes of reasoning, composition and deduction (Koskela et al., 2014), and activities, assembly and testing, to verify the construct against corresponding step in analysis, and to finally validate the design solution against client expectations. Verification is considered as rational and validation as plausible, subject to customer value judgment.

Thus, as opposed to dominant view in design literature (Roozenburg, 1993, Jones, 1992), analysis is creative too and concerned with devising a plan of action (means) to arrive at the desired result (ends). Synthesis is the implementation of the developed plan (Polya, 2014). Both streams of inference and action are subject to the properties of the abductive reasoning (Kroll and Koskela, 2016).

\subsection{Rhetoric as a Plausible Reasoning}

Partly due to the developments in the philosophy and epistemology of science, studying design as a rhetorical inquiry has captured extended attention within 20th century. Design has been considered as deliberative genre of rhetoric (Buchanan, 2001) - designers are concerned with questions of the best use of resources with the intention of the best interest of the audience (Herrick, 2015). Within this process, designers follow different lines of argumentation and pull knowledge from special and common places, similarly to the use of topoi (Burton, 1996) in classical rhetoric.

The design discourse begins with a problematic situation for new design (kairos) (Burton, 1996), a process for closing the gap between the currently unsatisfied customer needs and how things ought to be (Andreasen et al., 2015). The starting point of the rhetorical discourse is concerned with endoxa (common opinions) - the common ground about shared values, facts and presumptions between the designer and the customer/users (Koskela, 2015). Understanding the situation is necessary first step for designer to adapt to his/her audience by selecting the intention (Herrick, 2015). According to Perelman (2012), the four types of audiences include: universal, particular, audience of one; and oneself. For example, the society as a whole or the local government could represent the universal audience; customer and (potential) users the specific audience; colleague as the audience of one; and designer as an audience to oneself. 
As conceptualized by Buchanan (1985), a designer is not creating an object or a thing, but developing a persuasive argument for creating an effect on the audience. The object of communication, the design artefact, facilitates the engagement of the designer and its (potential) users into dialog. This rhetorical dialogic has several dimensions (Herrick, 2015): it requires forethought/planning/deliberation to adopt to audience/users/customers; it is guided by intention to receive compliance; and it invites response to test the ideas. Rhetorical process is a deliberation and weighing of alternatives, not proofs of the type of mathematicians use. Aristotle states that to deliberate is to reason through alternatives, no one does this when things cannot be "other than they are" (Perelman, 1971, Kennedy, 2007). Thus, rhetoric is a model for the plausible reasoning.

The original concept of rhetoric and rhetoric in design by Buchanan (2001) are concerned with rhetoric as practiced by an individual/designer. However, the division of labor and work have introduced the need for collaboration in design and making (Koskela, 2015). In design practice, design is to a large extent co-created by different specialized disciplines developing persuasive means for meeting the ends (Andreasen et al., 2015, Koskela, 2015). It is the intention embedded in the design object that links designer to users (potential users), but also designer to designers and/or makers (contractors). Thus, the design product/object becomes a common denominator for everybody involved, either as an objective or work at hand within the conversation.

This principle of intention effectiveness connects other elements, including the transmission of rules (transferring best practices and patterns from previous experience to new one); usage of the fundamental arguments (lines of argumentation, topoi); and invention and development of alternatives, requirements, issues, and ideas. Transmission of rules (solution principles and methods) from previous work and experience to new work is thus an essential dimension of design.

The need to persuade, but also to judge emerges from the fact that design deals with the probable and particular (Koskela, 2015). In design, it is not possible to attend all the possible future conditions in use that prevent the causal relationships holding. Therefore, design requires reasoning concerning probable (Koskela, 2015).

Furthermore, it is the user/customer's subjectivity of changing values and needs related to the artefact that are limiting the applicability of necessary reasoning, drawing knowledge solely from the episteme (Rittel and Webber, 1973, Buchanan, 1992). The establishment of design criteria is a problem of competing values and priorities. Thus, it is the limited predictability of all future circumstances and "wicked" nature of design problems that makes studying rhetoric as method for plausible (particular and probable) reasoning compelling.

The object of the design communication is subject to three different appeals, involving interrelated qualities of useful (logos), desirable (ethos) and usable (pathos) (Buchanan, 1985). Designers must skillfully blend these three elements in design argument (artefact), to gain compliance to their ideas. For developing the design argument, Buchanan (2001) proposed a set of "fundamental arts of design thinking" for diffusing the appeals, form and medium. These are somewhat in parallel to traditional canons of rhetoric, including (Kennedy, 2007, Koskela, 2015): Inventio, (invention) is concerned with the design circumstances and common ground, audience, intention and invention of requirements, issues and ideas; Dispositio (arrangement) is concerned with decomposition and composition; Elocutio (style) refers to the communication (embodiment) of design information into medium throughout the design stages; Memoria (memory) is concerned with design artefacts, representations of accumulated design knowledge; and Actio (delivery) is concerned with the delivery of designs. 
In summary, rhetoric is an art of inventive and persuasive communication forming a common system for setting, content, aim and means (Joost and Scheuermann, 2007). It is essentially the relationship, interaction between rhetor and audience, brought together in variety of objects (medium) of communication. This link is best described by Burton (1996) who states that the central rhetorical principle requires rhetor's words and subject matter be aptly fit to each other, to the circumstances and occasion (kairos), the audience and the speaker.

\subsection{Interpretation and Comparison of Two Design Conceptualizations}

Table 1 summarizes the different dimensions and aspects of the proto-theory of design and rhetoric. The starting point for proto-theory of design is a given design problem, while for rhetoric it is the given context/situation for understanding the particular and probable. If in analytical design problems or design requirements are assumed to be given (Vermaas, 2013), then in rhetoric only the design situation is given and requirements, issues and ideas need to be invented. For example Jensen (2011) and Emmitt and Ruikar (2013) have developed dynamic briefing method for continued customer/user involvement for understanding the design situation and customer values. The same briefings are used for evaluating the proposed designs too, representing the rhetorical dimension of design communication. On the other hand, the quality function deployment could be considered as a systematic study of user needs and requirements (Akao, 2004), guided by the necessary reasoning.

In both design concepts, there are two time periods in design, namely analysis and synthesis in proto-theory, and invention and delivery in rhetoric. These two time periods are proposed for example in an integrative design model, including discovery and design embodiment/construction (Reed, 2009). According to proto-theory, designers progress through two step abductive reasoning (Kroll and Koskela, 2016): from requirements to concepts and from concepts to structure/form; and in rhetorical design from invention (inventio) to arrangement (dispositio) to embodiment (elocutio). Within these two concepts, different modes of reasoning are used, in the proto-theory designers use transformation, regression and decomposition in analysis; and deduction and composition in synthesis. In rhetoric designers use argumentation and abduction (experience and intuition). Methods such as integral morphological charts (Zeiler and Savanovic, 2009), building information modelling, drawings, specifications, unit tests, checklists and quality management techniques have been used for systematic decomposition of requirements, concepts and solutions, and composition and deduction for assembling and testing more holistic solutions.

Analytical design and rhetoric represent necessary and plausible reasoning, respectively, the former based on the universal and certain, and the latter based on the probable and particular. Designers draw from common and specific places (topoi) to invent means for ends and advance towards different appeals in necessary (useful) and plausible reasoning (desirable and usable). However, the two step abductive reasoning in the prototheory of design also involves drawing from experience and intuition when developing and selecting between alternative means (Kroll and Koskela, 2016). Zeiler and Savanovic (2009) proposed to use the integral (collaborative) and morphological CK theory for multidisciplinary building design, requiring designers to carry out all modes of reasoning.

The relation between parts and whole is unproblematic (a whole can be divided into parts, and parts can be put together into the whole) in analytical design, while problematic in rhetoric. Within the latter the focus is on the whole, requiring also assembling partial wholes (Koskela and Ballard, 2013). This means that the design and making are 
cyclic/repeating within all the stages of design process. However, in the different stages of design, the focus is on one of the four domains, including activity, organ, parts and process (Andreasen et al., 2015). This is an important and valuable insight to production science, meaning that rhetoric proposes building artefacts (representations as physical or digital models) already during the design for the purpose of testing ideas on design audience.

In terms of collaboration, the proto-theory of design is more focused on the internal argumentation of individual designer. Rhetoric on the other hand lends itself to the service of planning and coordination as design is to large extent co-created by different specialized disciplines developing persuasive means for meeting the ends (Andreasen et al., 2015, Koskela, 2015). People need to work together because of the common objectives, interdependent activities and parts that must fit together to function and behave as required (Koskela, 2016, Pikas et al., 2016).

The targeted outcome in the proto-theory is the proof that the targeted technical artefact can be constructed with intended functions and behavior, while in rhetoric it is the persuasion of audience and their judgment (validation). As summarized by Buchanan (2001): "If a product is persuasive in the debate about how we should lead our lives, it is so because a designer has achieved a powerful and compelling balance of what is perceived to be useful, desirable and usable."

Table 1. Summary and comparison of the two design conceptualizations.

\begin{tabular}{|l|l|l|}
\hline Characteristics & Proto-Theory of Design & Rhetoric in Design \\
\hline Starting point & Given design problem & $\begin{array}{l}\text { Given situation (common ground, audience, } \\
\text { intention and ideas) }\end{array}$ \\
\hline Time Periods & Definition and embodiment construction & Invention and delivery \\
\hline Stages & $\begin{array}{l}\text { Two step abductive reasoning: function to } \\
\text { concept to structure/form }\end{array}$ & $\begin{array}{l}\text { Invention (inventio) of issues, ideas and } \\
\text { requirements, arrangement (dispositio) and } \\
\text { embodiment (elocutio) }\end{array}$ \\
\hline Modes of Reasoning & $\begin{array}{l}\text { Necessary reasoning (certain and } \\
\text { universal) }\end{array}$ & Plausible reasoning (probable and particular) \\
\hline Types of Reasoning & $\begin{array}{l}\text { Transformation, regression and } \\
\text { decomposition in analysis; and deduction } \\
\text { and composition in synthesis }\end{array}$ & $\begin{array}{l}\text { Argumentation and abduction (experience and } \\
\text { intuition) }\end{array}$ \\
\hline Types of Activities & $\begin{array}{l}\text { Communication, assembly, testing, } \\
\text { verification }\end{array}$ & Delivery, Validation \\
\hline $\begin{array}{l}\text { Persuasion Strategies } \\
\text { (Appeals) }\end{array}$ & Useful (Logos) & Desirable (Ethos) and usable (Pathos) \\
\hline Creativity & $\begin{array}{l}\text { Finding alternative means or chains of } \\
\text { means }\end{array}$ & In inventing topics and in composition \\
\hline Whole and parts & Simple, tractable & Complex, intractable \\
\hline Representation & In the thing (artefact) itself & Physical and digital models \\
\hline Social Interaction & Internal argumentation & Communication as a means for collaboration \\
\hline Standardization & Elements, parts and methods & $\begin{array}{l}\text { Persuasion of customer, user and judgement } \\
\text { (desirable and usable) }\end{array}$ \\
\hline Output & Proof of product (useful) & \\
\hline
\end{tabular}

\section{CONCLUSIONS}

Within this study, we have developed a theoretical base for the design science research (DSR) activity to be carried out within the third paper. The two complementary concepts of the proto-theory of design and design rhetoric provide the necessary prescriptions for understanding the nature of the design task. The latter implies that artefacts are not merely static things, but rather have an active role in shaping the human (customer's and users') context. In rational reasoning, we ascend from given premises to conclusions that directly derive from these. The proto-theory of design is concerned with the design and making of 
the artefact itself. In design rhetoric, premises are not assumed to be given and the design inquiry commences with the identification of the common ground, selecting the intention and the invention of means contributing to the three appeals of "useful, desirable and usable". As a result of the theoretical investigation to develop the knowledge base for design management, several aspects of the design get clarified, including design inferences (modes and types of design reasoning), processes (types and modes of design activities) and strategies. We also most consider that the creative nature of the design process sets extra challenges to managing design.

\section{REFERENCES}

Akao, Y. (2004). Quality Function Deployment: Integrating Customer Requirements Into Product Design. New York, USA, Productivity Press.

Andreasen, M. M., C. T. Hansen and P. Cash (2015). Conceptual Design: Interpretations, Mindset and Models, Springer.

Aristotle (2001). The Basic Works of Aristotle. New York, Modern Library Classics.

Buchanan, R. (1985). "Declaration by design: Rhetoric, argument, and demonstration in design practice." Design Issues: 4-22.

Buchanan, R. (1992). "Wicked problems in design thinking." Design issues: 5-21.

Buchanan, R. (2001). "Design and the new rhetoric: Productive arts in the philosophy of culture." Philosophy and Rhetoric 34(3): 183-206.

Buchanan, R. (2009). Thinking about Design: An Historical Perspective. Philosophy of Technology and Engineering Sciences. A. Meijers. Amsterdam, North-Holland: 409453.

Burton, G. O. (1996). The Forest of Rhetoric: silva rhetoricae, Brigham Young University.

Emmitt, S. and K. Ruikar (2013). Collaborative design management, Routledge.

Herrick, J. A. (2015). History and Theory of Rhetoric: An Introduction, Routledge.

Hevner, A. R. (2007). "A three cycle view of design science research." Scandinavian journal of information systems 19(2): 4.

Jensen, P. A. (2011). "Inclusive briefing and user involvement: case study of a media centre in Denmark." Architectural engineering and design management 7(1): 38-49.

Jones, J. C. (1992). Design Methods, John Wiley and Sons.

Joost, G. and A. Scheuermann (2007). Design as rhetoric. Basic principles for design research. 3rd Symposium of Swiss Design Network. Retrieved March.

Kennedy, G. A. (2007). On Rhetoric: A Theory of Civic Discourse, Translated with Introduction, Notes, and Appendices by Gregory Kennedy New York Oxford University Press.

Koskela, L. (2000). An exploration towards a production theory and its application to construction, VTT Technical Research Centre of Finland.

Koskela, L. (2015). Where rhetoric and lean meet. In: Proc. 23rdAnn. Conf. of the Int'l. Group for Lean Construction. Perth, Australia: 527-535.

Koskela, L. (2016). Presentation - Collaboration: Why is it needed? What does it require? Aalto Univeristy, Espoo, Finland.

Koskela, L. and G. Ballard (2012). "Is production outside management?" Building Research \& Information 40(6): 724-737.

Koskela, L., R. Codinhoto, P. Tzortzopoulos and M. Kagioglou (2014). The Aristotelian proto-theory of design. An Anthology of Theories and Models of Design, Springer: 285-303. 
Koskela, L. and M. Kagioglou (2006). The proto-theory of design: the method of analysis of the ancient geometers. DS 36: Proceedings DESIGN 2006, the 9th International Design Conference, Dubrovnik, Croatia.

Koskela, L. J. and G. Ballard (2013). The two pillars of design theory: Method of analysis and rhetoric. International Conference on Engineering Design, ICED13, 19-22 August 2013, Sungyunkwan University, Seoul, Korea, The Design Society.

Kroes, P. (2002). "Design methodology and the nature of technical artefacts." Design Studies 23(3): 287-302.

Kroll, E. and L. Koskela (2014). On the problem of abduction in design. Design Computing and Cognition DCC'14. London, Springer.

Kroll, E. and L. Koskela (2016). "Explicating concepts in reasoning from function to form by two-step innovative abductions." Artificial Intelligence for Engineering Design, Analysis and Manufacturing 30(02): 125-137.

Kuechler, B. and V. Vaishnavi (2011). Extending prior research with design science research: two patterns for DSRIS project generation. Service-Oriented Perspectives in Design Science Research, Springer: 166-175.

Meos, I. (2011). Antiikfilosoofia. Peatükke filosoofia ajaloost.

Perelman, C. (1971). The new rhetoric. Pragmatics of natural languages, Springer: 145149.

Perelman, C. (2012). The new rhetoric and the humanities: essays on rhetoric and its applications, Springer Science \& Business Media.

Pikas, E., L. Koskela, N. Treldal, G. Ballard and R. Liias (2016). Collaboration in Design Justification, Characteristics and Related Concepts. 24th Annual Conference of the International Group for Lean Construction, Boston, USA.

Polya, G. (2014). How to solve it: A new aspect of mathematical method, Princeton university press.

Reed, B. (2009). The integrative design guide to green building: Redefining the practice of sustainability, John Wiley \& Sons.

Rittel, H. W. and M. M. Webber (1973). "Dilemmas in a general theory of planning. "Policy sciences 4(2): 155-169.

Roozenburg, N. F. M. (1993). "On the pattern of reasoning in innovative design." Design Studies 14(1): 4-18.

Ullman, D. (2009). The Mechanical Design Process, McGraw-Hill Education.

Vermaas, P. E. (2013). "The coexistence of engineering meanings of function: four responses and their methodological implications." Artificial Intelligence for Engineering Design, Analysis and Manufacturing 27(03): 191-202.

Zeiler, W. and P. Savanovic (2009). "Integral morphological Ck design approach for multidisciplinary building design." Architectural Engineering and Design Management 5(4): 193-214. 